\title{
A BRINQUEDOTECA ENQUANTO AMBIENTE RESTAURADOR PARA A CRIANÇA HOSPITALIZADA: UMA ANÁLISE INTEGRATIVA
}

\author{
THE TOY LIBRARY AS A RESTORING ENVIRONMENT FOR THE \\ HOSPITALIZED CHILDREN: AN INTEGRATIVE ANALYSIS
}

\section{LA SALA DE JUEGOS COMO ENTORNO RESTAURANTE PARA NIÑOS HOSPITALIZADOS: UN ANÁLISIS INTEGRATIVO}

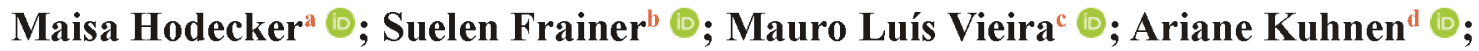 \\ ${ }^{a}$ Psicóloga. Mestranda em Psicologia pela Universidade Federal de Santa Catarina, Florianópolis/SC, Brasil. Bolsista CAPES-DS. \\ E-mail: maisa_hodecker@hotmail.com \\ ${ }^{b}$ Pós-graduanda em Avaliação Psicológica pelo Instituto de Pós-graduação e graduação - IPOG, Florianópolis/SC, Brasil. Assistente \\ de recursos humanos do Hospital Nossa Senhora do Perpétuo Socorro (Gaspar-SC). E-mail: suelenfrainer@gmail.com \\ 'Doutor em Psicologia Experimental pela Universidade de São Paulo, com estágio pós-doutoral na Dalhousie University em Halifax \\ (Canadá) e no Instituto de Psicologia da Universidade Federal do Rio Grande do Sul. Professor Titular do Departamento de Psicolo- \\ gia na Universidade Federal de Santa Catarina, Florianópolis/SC, Brasil. E-mail: maurolvieira@gmail.com

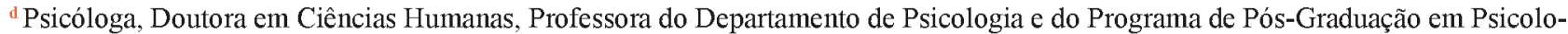 \\ gia da Universidade Federal de Santa Catarina. \\ E-mail: arianekuhnen@gmail.com
}

\begin{abstract}
Resumo: O objetivo deste estudo foi identificar a produção de artigos científicos envolvendo a importância da brinquedoteca para o desenvolvimento infantil da criança hospitalizada, publicados em âmbito nacional entre 2008 até abril de 2018. Utilizou-se os descritores "brinquedo", "hospital" e "criança" nas bases de dados: IndexPsi (06), SciELO (21), PePSIC (04), LILACS (60) e Periódicos CAPES (60). Obteve-se o total de 151 resultados. Após a aplicação de critérios de inclusão e exclusão, a amostra consistiu em 10 artigos científicos. Realizou-se uma análise sistemática dos achados, levantando seis categorias temáticas que contemplam as principais contribuições da brinquedoteca hospitalar: 1) continuidade no desenvolvimento infantil; 2) humanização do atendimento; 3) interação social; 4) alívio dos efeitos emocionais decorrentes da internação; 5) o lúdico como fator de aprendizagem; e 6) distração. Foi consenso que a brinquedoteca
\end{abstract}

Como citar o artigo: HODECKER, M.; FRAINER, S.; VIEIRA, M. L.; KUHNEN, A. A brinquedoteca enquanto ambiente restaurador para a criança hospitalizada: uma análise integrativa. Revista de Ciências Humanas, Florianópolis, v. 53, 2019 DOI: 10.5007/2178-4582.2019.e57292 você pode compartilhar, adaptar, para qualquer fim, desde que atribua a autoria da obra, forneça um link para a licença, e indicar se foram feitas alterações. 
configura-se um ambiente que possibilita a humanização do cuidado e traz benefícios para a criança, aos profissionais e acompanhantes.

Palavras-chave: Brinquedo; Criança; Hospital; Psicologia Ambiental.

\begin{abstract}
The aim of this study was to identify the production of scientific articles involving the importance of the toy library for the child development of hospitalized children, published nationwide between 2008 and April 2018. The keywords "toy", "hospital" and "child" were used in the databases: IndexPsi (06), SciELO (21), PePSIC (04), LILACS (60) and CAPES Journals (60). A total of 151 results were obtained. After applying inclusion and exclusion criteria, the sample consisted of 10 scientific papers. A systematic analysis of the findings was carried out, raising six thematic categories that contemplate the main contributions of the hospital toy library: 1) continuity in the child development; 2) humanization of care; 3) social interaction; 4) relief of the emotional effects of hospitalization; 5) the playful as a learning factor; and 6) distraction. It was agreed that the toy library is an environment that enables the humanization of care and brings benefits to the child, professionals and caregivers.
\end{abstract}

Keywords: Toy; Child; Hospital; Environmental Psychology.

Resumen: El objetivo de este estudio fue identificar la producción de artículos científicos relacionados con la importancia de la sala de juegos para el desarrollo infantil de niños hospitalizados, publicados en todo el país entre 2008 y abril de 2018. Los descriptores “juguete", "hospital" y "Niño" en las bases de datos: IndexPsi (06), SciELO (21), PePSIC (04), LILACS (60) y CAPES Journals (60). Se obtuvieron un total de 151 resultados. Después de aplicar los criterios de inclusión y exclusión, la muestra consistió en 10 artículos científicos. Se realizó un análisis sistemático de los hallazgos, generando seis categorías temáticas que contemplan las principales contribuciones de la sala de juegos del hospital: 1) continuidad en el desarrollo infantil; 2) humanización de la atención; 3) interacción social; 4) alivio de los efectos emocionales de la hospitalización; 5) lo lúdico como factor de aprendizaje; y 6) distracción. Se acordó que la sala de juegos es un entorno que permite la humanización de la atención y brinda beneficios para el niño, los profesionales y los cuidadores.

Palabras clave: juguete; Niño; Hospital; Psicología Ambiental.

\title{
1 INTRODUÇÃO
}

No Brasil, a importância do lúdico e sua implicação na recuperação da criança hospitalizada vem sendo valorizada, principalmente após ser sancionada a Lei Federal $n^{\circ} 11.104$, de 21 de março de 2005 (BRASIL, 2005) que estabelece a obrigatoriedade da implementação de brinquedotecas em hospitais com internação pediatria. Outro fator atrelado a esse avanço diz respeito a humanização do atendimento em saúde. De acordo com o Art. $2^{\circ}$ dessa lei vigente, a brinquedoteca deve dispor de brinquedos e jogos educativos, que promovam estímulos a criança hospitalizada (OLIVEIRA, et al., 2009).

Embora essa lei esteja em vigor, a existência de brinquedotecas em hospitais ainda está em processo de implementação. Uma das problemáticas enfrentadas pelas instituições de saúde diz respeito a própria legislação, que não oferece parâmetros consistentes para a estruturação e funcionamento da brinquedoteca, não garantindo uma uniformidade e padronização destes espaços (MELLO, et al., 1999). Assim, a brinquedoteca nos hospitais permanece a mercê dos próprios profissionais da saúde que irão elaborar e dialogar sobre as intervenções, práticas educativas, horários e funcionamento da brinquedoteca (LOPES; PAULA; ANGELI, 2012).

Nesse sentido, a implementação das brinquedotecas em hospitais serve para humanizar não somente o atendimento e as intervenções, como o próprio ambiente em si. Como a brinquedoteca traz consigo elementos físicos coloridos, o lúdico, a diversão, a brincadeira, propicia a criança uma minimização da hostilidade em relação ao hospital, alívio das reações emocionais e psicológicas decorrentes da internação, assim como um atendimento não somente voltado à questões relativas a saúde biológica e física da criança, como também ao desenvolvimento saudável para as crianças e suas famílias (MELO; VALLE, 2010).

Aos olhos de uma criança, a brinquedoteca no ambiente hospitalar pode atenuar o estresse e aumentar as sensações de bem-estar. Além disso, possibilita melhores condições de permanência para 
casos de internação contínua, mais alegria, recuperação facilitada, adesão ao tratamento e continuidade no processo de desenvolvimento. Por conta disso, a brinquedoteca é vista como um ambiente restaurador do estresse inserido no hospital, acrescendo a este contexto não somente a capacidade de gerar estresse como de retê-lo. A Psicologia Ambiental inserida nestes espaços hospitalares promove a humanização e bem-estar, desde perspectivas direcionadas a pacientes e acompanhantes, até profissionais da saúde. Esta área investiga a inter-relação entre homem-ambiente e suas respectivas influencias. Sua visão de homem indica que tanto o ambiente influencia o homem, quanto o processo inverso. Assim, mesmo que emergido na inconsciência, o homem está a todo momento sofrendo a influência do ambiente (MUSSA; MALERBI, 2008).

Nesse sentido, embora o hospital esteja cercado de elementos físicos que remetem a dor, sofrimento e enfermidades, possui a capacidade de promover uma melhor condição para o paciente recuperar e restabelecer sua condição a priori de saúde através de ambientes restauradores somado a qualidade do tratamento prestado. Logo, o brincar impulsiona o desenvolvimento humano, fazendo a criança apreender o mundo circundante e fazendo-a participar ativamente da cultura lúdica e daquela construída com sua família. Deste modo, a brinquedoteca repercute benefícios à criança em exercitar suas capacidades motoras, cognitivas e socioafetivas, mesmo durante um tratamento de saúde (ULRICH, 1983).

Percebendo a importância e função da brinquedoteca hospitalar para o desenvolvimento infantil, este estudo objetivou identificar a produção de artigos científicos envolvendo a importância da brinquedoteca para o desenvolvimento infantil da criança hospitalizada, publicados em âmbito nacional entre 2008 até abril de 2018. Além disso, este estudo poderá fomentar novas pesquisas para além de contextos hospitalares, mas também em outras instituições, viabilizando o atendimento humanizado e analisando o ambiente como potencial restaurador psicológico.

\section{MÉTODO}

Trata-se de um estudo qualitativo de revisão integrativa, que por sua vez, viabiliza a elaboração de uma síntese e conclusão dos dados encontrados na pesquisa acerca da temática da brinquedoteca hospitalar. Para tanto, o primeiro passo consistiu em formular uma pergunta norteadora, selecionar os descritores e bases de dados, coletar e avaliar os dados, analisar e interpretar os dados e organizar os resultados (MENDES; SILVEIRA; GALVÃO, 2008). Dessa forma, para direcionar a pesquisa formulou-se a seguinte pergunta: Qual a importância da brinquedoteca hospitalar, segundo a produção científica brasileira de 2008 a abril de 2018 , no que tange ao desenvolvimento infantil da criança hospitalizada?

Inicialmente foi realizada uma busca de artigos científicos sobre a temática da brinquedoteca hospitalar publicados entre 2008 e abril de 2018. A busca foi realizada nas seguintes bases de dados: IndexPsi, Scientific Electronic Library Online (SciELO), Portal de Periódicos Eletrônicos de Psicologia (PePSIC), Literatura Latino-Americana e do Caribe em Ciências da Saúde (LILACS) e Periódicos da Coordenação de Aperfeiçoamento de Pessoal de Nível Superior (CAPES). Os descritores selecionados a partir da busca no Descritores em Ciências da Saúde (DeCS) para rastrear as publicações foram: brinquedo, hospital e criança. Os descritores foram pesquisados de forma conjunta com o uso do operador booleano AND entre eles. Optou-se por classificar nas bases de dados somente estudos realizados no Brasil, em idioma português, disponibilizados por completo, entre o período determinados.

Realizado o levantamento da produção científica já refinada com as referidas classificações, ocorreram os seguintes procedimentos: a) leitura dos resumos e análise do conteúdo geral; b) exclusão de artigos incompletos, duplicados e/ou não científicos; c) reconhecer se havia a temática "brinquedoteca hospitalar" ou sua evidência no decorrer do conteúdo apresentado; d) os artigos que sanaram os critérios anteriores foram lidos integralmente; e e) a partir da leitura, foram selecionadas as temáticas mais recorrentes para contemplar as categorias de análise do corpo deste trabalho. Como visto, os critérios de inclusão, respectivamente, foram: a) artigos publicados entre 2008 e 2018; b) artigos dis- 
poníveis para acesso livre e na integra; c) em idioma português; e d) artigos que discorressem sobre a brinquedoteca hospitalar.

Não foram incluídas patentes e citações, livros, E-books, trabalhos acadêmicos incompletos ou de outras modalidades (monografia, dissertação, tese, trabalho apresentado em congresso, etc.). Além disso, não foram contemplados na pesquisa artigos fora do período determinado, que discorriam apenas sobre brinquedo terapêutico ou o lúdico, sem a evidência no transcorrer do artigo acerca da brinquedoteca hospitalar, já que este configura-se uma ferramenta e não um espaço no hospital disponível a criança. Nesse sentido, buscou-se artigos que contemplavam a brinquedoteca e sua importância no desenvolvimento da criança hospitalizada.

A triagem se iniciou após a identificação de 151 artigos científicos a partir dos descritores nas bases de dados. Em seguida, os resumos foram importados para o EndNote versão 5.1.34 para realizar a leitura seletiva dos artigos, partindo dos títulos e resumos, para posterior analisar de forma exploratória, sistemática e analítica o conteúdo integral do artigo. Na fase de elegibilidade, excluíram-se os artigos que não estavam em acesso aberto, carta, editorial, artigos de outra modalidade acadêmica (trabalho apresentado em congresso, teses, dissertações, monografias), e aqueles que estavam duplicados. Além da leitura, houve novamente a aplicação dos critérios de inclusão e exclusão para verificar se realmente todos seriam contemplados na pesquisa. Na fase de inclusão, os artigos que restaram após o refinamento foram lidos integralmente e novamente aplicou-se os critérios de inclusão e exclusão para averiguar a veracidade dos resultados obtidos, como visto na Figura 1.

Figura 1: Fluxograma da busca de periódicos.

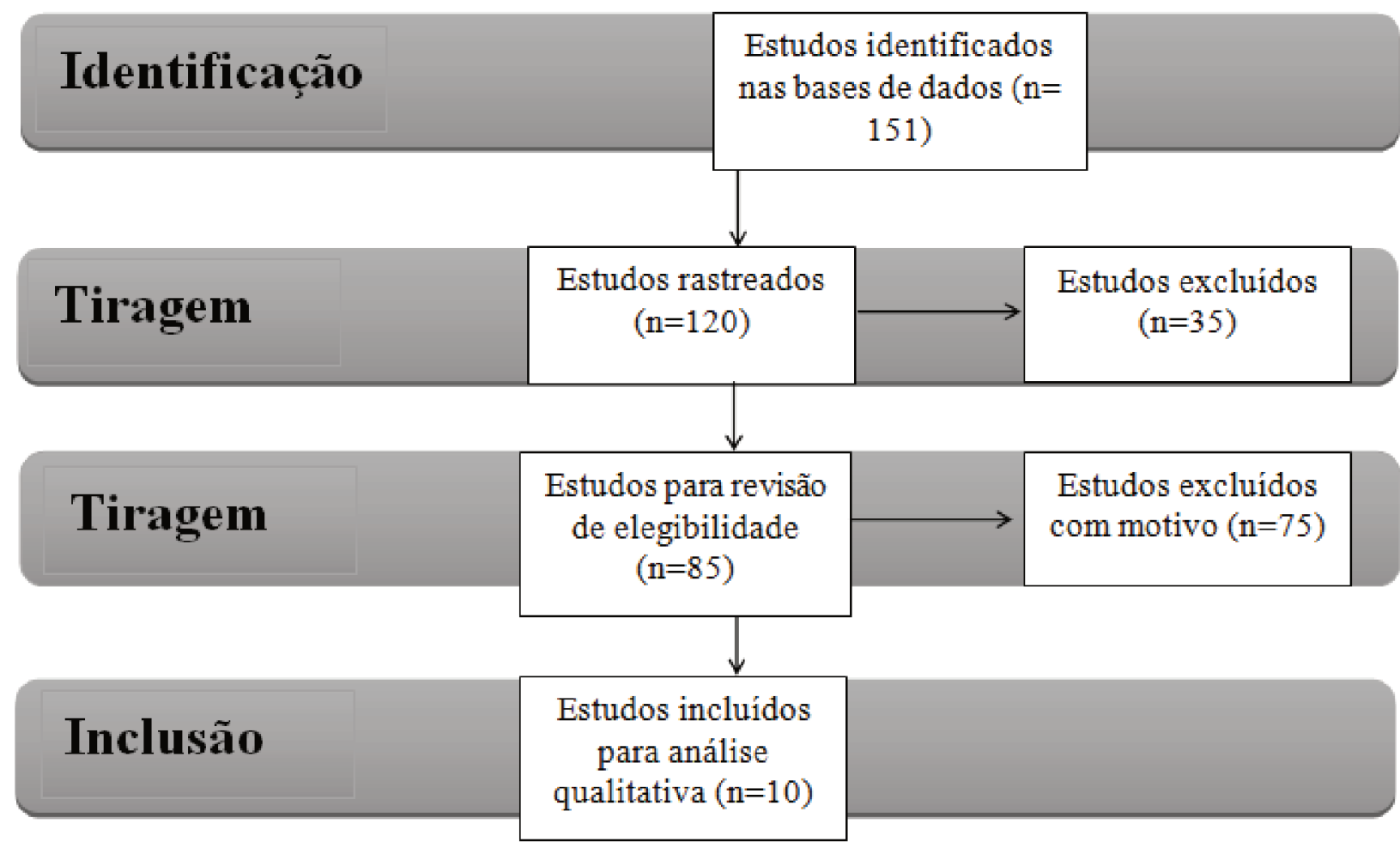

Fonte: Elaborado pelos autores, 2018.

Para garantir resultados válidos, os estudos selecionados foram analisados de forma crítica, buscando analisar as potencialidades, as fragilidades de cada estudo, as semelhanças entre cada 
resultado dos estudos e as controversas. A apresentação dos resultados sucedeu de forma descritiva a posteriori a compilação dos artigos selecionados. Os resultados principais foram sistematizados na Tabela 1, que revela as devidas especificações dos artigos, semelhanças nos resultados e dados relevantes que os diferenciam uns dos outros. Para discutir os resultados, acrescentou-se a teoria levantada a partir da análise dos artigo a Psicologia Ambiental, mais especificamente a temática dos ambientes restauradores e sua capacidade de amenizar o estresse decorrente da internação hospitalar.

\section{RESULTADOS}

De início, utilizando os descritores juntos nas bases de dados IndexPsi, SciELO, PePSIC, LILACS e Periódicos CAPES foi obtido 151 resultados (IndexPsi=06; SciELO=21; PePSIC=04; LILACS=60; Periódicos CAPES=60). Ao aplicar os critérios de inclusão e exclusão já descritos, destes 151 resultados, 31 foram exclusos inicialmente por estarem fora do período pré-determinado (2012 a abril de 2018), restando 120 resultados. Destes, 35 não estavam disponíveis na integra para acesso, sendo exclusos da análise. Os 85 artigos científicos restantes foram selecionados para a análise da elegibilidade, aplicando os critérios de inclusão e exclusão para a segunda filtragem.

Por fim, 75 artigos foram descartados: 15 artigos exclusos por serem oriundos de estudos internacionais e em língua estrangeira; 37 por estarem em desacordo com o tema proposto; 12 foram excluídos pois tratavam-se de trabalhos de outras modalidades acadêmicas; 11 foram excluídos por tratar de temáticas semelhantes (brinquedo terapêutico ou o lúdico no hospital), porém sem englobar em sua análise a brinquedoteca hospitalar. Dessa forma, a amostra desta pesquisa consistiu em 10 artigos científicos. Ao reler na integra os artigos contemplados, foram encontradas similaridades nos assuntos abordados. A partir disso, para organizar os dados e qualificar a apresentação das premissas, foram criadas categorias temáticas dos assuntos mais relevantes, triviais e que estavam condizentes com os objetivos da presente pesquisa. Os suprassumos dos artigos selecionados são expostos na Tabela 1.

No que concerne aos temas abordados nos artigos, após o levantamento, os temas foram subdivididos em categorias temáticas para posterior discussão teórica. Na Tabela 2, as categorias temáticas foram distribuídas conforme frequência de citação nos achados. Assim, em ordem crescente de temáticas, cada categoria levantada aborda uma ou mais contribuições que a brinquedoteca hospitalar pode proporcionar aos seus usuários, principalmente aqueles hospitalizados. Nesse sentido, as temáticas mais relevantes extraídas dos achados foram compiladas e discutidas teoricamente. Como expresso na Tabela 2, as categorias temáticas emergidas foram: 1) continuidade no desenvolvimento infantil: a possibilidade de usufruir do espaço da brinquedoteca como um instrumento para potencializar aprendizados ou promover novos ensinamentos enquanto a criança está afastada de seu cotidiano escolar habitual; 2) humanização do atendimento: possibilidade de usufruir do espaço para tornar o contato profissional menos amedrontador à crianças e, consequentemente, oportunizar uma aproximação maior com os familiares e o paciente; 3) interação social: possibilidade de formação de vínculos afetivos com outras crianças hospitalizadas e aproximação entre familiares e profissionais da saúde; 4) alívio dos efeitos emocionais e psicológicos decorrentes da internação: possibilidade de utilizar o espaço como ferramenta terapêutica; 5) o lúdico como fator de aprendizagem: possibilidade de benefícios voltados ao desenvolvimento intelectual da criança hospitalizada por meio da brincadeira lúdica; e 6) distração: utilizar do espaço para esquecer momentaneamente dos sintomas e sentimentos negativos envolvidos no processo de hospitalização. Destaca-se que alguns artigos focalizaram em mais de uma temática, então haverá repetição de autores nas categorias. Nesse sentido, na Tabela 2 é exposta a relação de temáticas e respectivos autores que discutiram sobre o assunto. 
Tabela 1. Artigos contemplados na pesquisa

\begin{tabular}{|c|c|c|c|c|c|}
\hline $\begin{array}{c}\text { Bases de } \\
\text { dados }\end{array}$ & Autor e ano & Objetivo & $\begin{array}{l}\text { Revista } \\
\text { Científica }\end{array}$ & $\begin{array}{c}\text { Tipo de } \\
\text { Estudo/Delineament }\end{array}$ & Principais Resultados \\
\hline 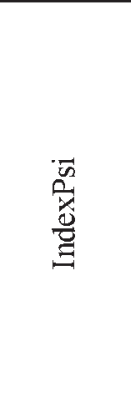 & $\begin{array}{c}\text { 1. Mussa e } \\
\text { Malerbi } \\
(2008)\end{array}$ & $\begin{array}{c}\text { Avaliar o impacto das } \\
\text { atividades lúdicas } \\
\text { realizadas com crianças } \\
\text { hospitalizadas acerca de } \\
\text { seu estado emocional e } \\
\text { queixas de dor. }\end{array}$ & $\begin{array}{c}\text { Psicologia: } \\
\text { Teoria e Prática }\end{array}$ & $\begin{array}{l}\text { Estudo qualitativo, } \\
\text { do tipo descritivo- } \\
\text { exploratório, } \\
\text { transversal }\end{array}$ & $\begin{array}{l}\text { Verificou-se que o lúdico produz } \\
\text { efeitos positivos sobre o estresse da } \\
\text { criança. Por meio de atividades lúdicas } \\
\text { e do ambiente diferenciado que a } \\
\text { criança hospitalizada poderá ser } \\
\text { favorecida, tanto física quanto } \\
\text { emocionalmente. Assim, o lúdico } \\
\text { favorece o controle das emoções, a } \\
\text { aceitação da doença e facilita a } \\
\text { recuperação. }\end{array}$ \\
\hline 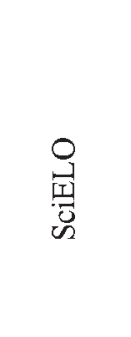 & $\begin{array}{c}\text { 2. Melo e } \\
\text { Valle }(2010)\end{array}$ & $\begin{array}{c}\text { Compreender o sentido } \\
\text { de Ser-criança com } \\
\text { câncer em tratamento } \\
\text { ambulatorial, utilizando } \\
\text { a brinquedoteca como } \\
\text { fator de proteção. }\end{array}$ & $\begin{array}{c}\text { Revista da } \\
\text { Escola de } \\
\text { Enfermagem da } \\
\text { USP }\end{array}$ & $\begin{array}{c}\text { Estudo qualitativo à } \\
\text { luz do referencial } \\
\text { fenomenológico de } \\
\text { Heidegger }\end{array}$ & $\begin{array}{l}\text { O estudo verificou que a criança } \\
\text { hospitalizada atravessa um dilema, um } \\
\text { constante ir e vir permeado pela } \\
\text { sensação ora de autenticidade, ora de } \\
\text { inautenticidade. O lúdico neste espaço } \\
\text { de recuperação promove o acesso a } \\
\text { vivencias da criança favorecendo sua } \\
\text { expressão e retomada da autenticidade. }\end{array}$ \\
\hline 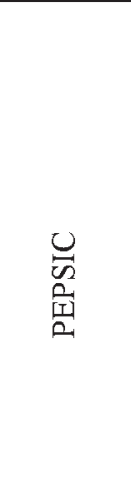 & $\begin{array}{l}\text { 3. Sossela e } \\
\text { Sager } \\
(2017)\end{array}$ & $\begin{array}{c}\text { Investigar os beneficios } \\
\text { que o lúdico oferta a } \\
\text { criança ho spitalizada e } \\
\text { analisar o efeito do uso } \\
\text { do brinquedo nas } \\
\text { interações da criança. }\end{array}$ & $\begin{array}{l}\text { Sociedade } \\
\text { Brasileira de } \\
\text { Psicologia } \\
\text { Hospitalar }\end{array}$ & $\begin{array}{c}\text { Estudo qualitativo, } \\
\text { do tipo exploratório, } \\
\text { bibliográfico. }\end{array}$ & $\begin{array}{l}\text { Os resultados apontam que o lúdico } \\
\text { ofertado pela brinquedoteca é um } \\
\text { procedimento necessário à reabilitação } \\
\text { da criança hospitalizada, por conta } \\
\text { disso é obrigatório por Lei como um } \\
\text { direito da criança ter acesso a esses } \\
\text { espaços. O brinquedo é visto como } \\
\text { possibilidade da criança dar } \\
\text { continuidade em seu desenvolvimento, } \\
\text { assim como torna possivel a criança } \\
\text { ressignificar a dor e sofrimento } \\
\text { vivenciados pela hospitalização. }\end{array}$ \\
\hline 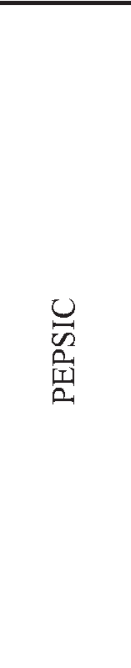 & $\begin{array}{l}\text { 4. Dietz e } \\
\text { Oliveira } \\
(2008)\end{array}$ & \begin{tabular}{|} 
Analisar a qualidade das \\
brinquedotecas \\
hospitalares, públicas e \\
particulares nas \\
unidades de saúde de \\
um município da \\
Grande São Paulo.
\end{tabular} & $\begin{array}{c}\text { Boletim } \\
\text { Academia } \\
\text { Paulista de } \\
\text { Psicologia }\end{array}$ & $\begin{array}{l}\text { Estudo qualitativo, } \\
\text { do tipo descritivo- } \\
\text { exploratório, } \\
\text { transversal }\end{array}$ & $\begin{array}{l}\text { Dentre as } 31 \text { Unidades de Saúde } \\
\text { encontradas no município, apenas duas } \\
\text { possuíam brinquedoteca, sendo uma } \\
\text { em unidade pública e a outra em } \\
\text { unidade particular. Embora estejam } \\
\text { instaladas, as brinquedotecas não } \\
\text { foram satisfatórias no quesito } \\
\text { planejamento e funcionamento. } \\
\text { Verificou-se que a brinquedoteca } \\
\text { hospitalar necessita da definição clara } \\
\text { de seus propósitos à criança e a } \\
\text { formação da equipe profissional deve } \\
\text { equiparar ao serviço ofertado. } \\
\text { Entretanto, analisou-se que os serviços } \\
\text { ofertados e o acolhimento a clientela } \\
\text { foram satisfatórios. }\end{array}$ \\
\hline
\end{tabular}




\begin{tabular}{|c|c|c|c|c|c|}
\hline 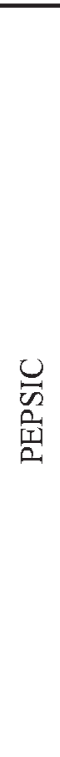 & $\begin{array}{l}\text { 5. Lopes, } \\
\text { Junior e } \\
\text { Oliveira } \\
(2015)\end{array}$ & \begin{tabular}{|c|} 
Analisa o \\
funcionamento de uma \\
brinquedoteca em um \\
hospital pediátrico de \\
uma cidade do Paraná.
\end{tabular} & $\begin{array}{l}\text { Boletim - } \\
\text { Academia } \\
\text { Paulista de } \\
\text { Psicologia }\end{array}$ & $\begin{array}{c}\text { Estudo qualitativo } \\
\text { do tipo Estudo de } \\
\text { Caso. }\end{array}$ & $\begin{array}{l}\text { Os resultados apontam que a } \\
\text { implementação de brinquedotecas em } \\
\text { hospitais configura-se r uma } \\
\text { problemática diante das exigências } \\
\text { internas de cada hospital. Os autores } \\
\text { apontam que quiçá seja por conta } \\
\text { desse entrave que a brinquedoteca } \\
\text { atravessa um processo problemático } \\
\text { para ser totalmente reconhecido e } \\
\text { aceito. A brinquedoteca disponibiliza a } \\
\text { criança o brincar como modo de } \\
\text { expressar-se, conviver com outras } \\
\text { crianças, assim como estreitar laços } \\
\text { com familiares e profissionais da saúde. } \\
\text { Além disso, verificou-se que a } \\
\text { brinquedoteca atua como ferramenta } \\
\text { para facilitar a adesão da criança ao } \\
\text { tratamento. }\end{array}$ \\
\hline 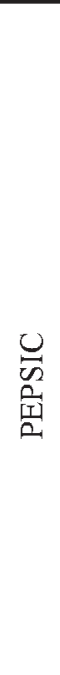 & $\begin{array}{c}6 . \\
\text { Oliveira, } \\
\text { et al. } \\
(2009)\end{array}$ & \begin{tabular}{|c|} 
Descrever atividades \\
desenvolvidas em um \\
projeto de extensão em \\
enfermaria pediátrica de \\
um hospital \\
universitário de \\
Florianópolis.
\end{tabular} & $\begin{array}{c}\text { Revista } \\
\text { Brasileira } \\
\text { Crescimento e } \\
\text { Desenvolviment } \\
\text { o Humano }\end{array}$ & $\begin{array}{c}\text { Estudo qualitativo, } \\
\text { descritivo- } \\
\text { exploratório, } \\
\text { transversal }\end{array}$ & $\begin{array}{l}\text { Conforme observado, a brinquedoteca } \\
\text { atendeu aos requisitos de ajudar a } \\
\text { criança a compreender e lidar com o } \\
\text { processo da doença e recuperação. } \\
\text { Além disso, a brinquedoteca } \\
\text { possibilitou uma melhor interação entre } \\
\text { criança hospitalizada e equipe médica. } \\
\text { Por fim, constatou-se que o lúdico } \\
\text { inserido no contexto hospitalar auxilia } \\
\text { a amenizar os traumas oriundos da } \\
\text { internação, já que crianças tendem a } \\
\text { vivenciar essa experiencia de modo } \\
\text { mais doloroso e diferenciado de } \\
\text { adultos e idosos, assim como facilita a } \\
\text { recuperação da criança, diminuindo o } \\
\text { tempo dedicado a internação. }\end{array}$ \\
\hline 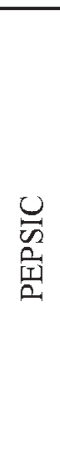 & $\begin{array}{l}\text { 7. Lima, et } \\
\text { al. }(2015)\end{array}$ & $\begin{array}{l}\text { Analisar a percepção de } \\
\text { acompanhantes de } \\
\text { crianças hospitalizar no } \\
\text { que concerne a } \\
\text { brinquedoteca } \\
\text { hospitalar. }\end{array}$ & $\begin{array}{c}\text { Revista } \\
\text { Psicologia: } \\
\text { Teoria e Prática }\end{array}$ & $\begin{array}{c}\text { Estudo qualitativo, } \\
\text { descritivo- } \\
\text { exploratório, } \\
\text { transversal }\end{array}$ & $\begin{array}{l}\text { Os acompanhantes descreveram a } \\
\text { brinquedoteca como um espaço } \\
\text { promotor de desenvolvimento para a } \\
\text { criança e de bem-estar, para ambos. } \\
\text { Além disso, os acompanhantes } \\
\text { descreveram este espaço como } \\
\text { provedor de da preservação da rotina } \\
\text { infantil usual da criança. Em suma, a } \\
\text { brinquedoteca foi avaliada como } \\
\text { espaço de promoção de saúde e } \\
\text { desenvolvimento. }\end{array}$ \\
\hline
\end{tabular}




\begin{tabular}{|c|c|c|c|c|c|}
\hline 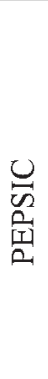 & $\begin{array}{c}8 . \\
\text { Bustamante, } \\
\text { et al. }(2014)\end{array}$ & $\begin{array}{c}\text { Descrever um relato de } \\
\text { experiência obtido } \\
\text { através de um projeto } \\
\text { "Crianças e famílias" no } \\
\text { setor de cardiologia } \\
\text { pediátrica de um } \\
\text { hospital público em } \\
\text { Salvador. }\end{array}$ & Revista EPOS & $\begin{array}{l}\text { Estudo qualitativo, } \\
\text { descritivo- } \\
\text { exploratório, } \\
\text { transversal }\end{array}$ & $\begin{array}{l}\text { Constatou-se que o brincar é uma } \\
\text { atividade que propicia prazer e } \\
\text { expressão de angustias à criança } \\
\text { hospitalizada. Verificou-se ainda que a } \\
\text { brinquedoteca não somente favorece o } \\
\text { desenvolvimento da criança, como a } \\
\text { permanência e acompanhamento de } \\
\text { familiares durante o processo de } \\
\text { recuperação da criança. }\end{array}$ \\
\hline 导 & $\begin{array}{l}\text { 9. Vitta, et } \\
\text { al. }(2015)\end{array}$ & $\begin{array}{l}\text { Investigar a perspectiva } \\
\text { de acompanhantes de } \\
\text { crianças hospitalizadas } \\
\text { acerca do brincar no } \\
\text { contexto hospitalar. }\end{array}$ & $\begin{array}{c}\text { Journal of } \\
\text { Human Growth } \\
\text { and } \\
\text { Development }\end{array}$ & $\begin{array}{l}\text { Estudo qualitativo, } \\
\text { do tipo descritivo- } \\
\text { exploratório, } \\
\text { transversal }\end{array}$ & $\begin{array}{l}\text { Constatou-se por meio da pesquisa que } \\
\text { o brincar propicia a criança uma } \\
\text { diferença, principalmente em duas } \\
\text { dimensões: favorece o enfrentamento } \\
\text { da enfermidade fisica e, como } \\
\text { consequência, facilita e agiliza o } \\
\text { processo de recuperação da criança. }\end{array}$ \\
\hline 怘 & $\begin{array}{c}\text { 10. Lima e } \\
\text { Magalhães } \\
(2013)\end{array}$ & $\begin{array}{c}\text { Investigar as condições } \\
\text { de serviços e espaços } \\
\text { das brinquedotecas } \\
\text { hospitalares em Belém } \\
\text { do Pará. }\end{array}$ & $\begin{array}{l}\text { Psicologia } \\
\text { Argumento }\end{array}$ & $\begin{array}{l}\text { Estudo qualitativo, } \\
\text { do tipo descritivo- } \\
\text { exploratório, } \\
\text { transversal }\end{array}$ & $\begin{array}{l}\text { Dentre os principais resultados da } \\
\text { pesquisa, estão: (a) todos os hos-pitais } \\
\text { da pesquisa eram públicos; (b) } \\
\text { verificou-se escassez de registros a } \\
\text { respeito da implantação e } \\
\text { funcionamento das brinquedotecas; (c) } \\
\text { no tocante ao acervo lúdico, este se } \\
\text { diferenciou em relação à quantidade; } \\
\text { (d) as equi-pes eram compostas por } \\
\text { diferentes números e formações } \\
\text { profissionais; (e) são oferecidas } \\
\text { atividades livres e dirigidas às crianças } \\
\text { hospitalizadas. }\end{array}$ \\
\hline
\end{tabular}

Fonte: Elaborado pelos autores, 2018.

Percebe-se que os temas principais estão relacionados a importância da brinquedoteca hospitalar, vista como um espaço que possibilita a criança uma continuidade do desenvolvimento, buscando aproximar-se da normalidade vivenciada antes da internação. Como consequência, a brinquedoteca torna-se um espaço e instrumento de humanização do atendimento à criança $\mathrm{e}$ modificação da visão generalista de que hospital é um contexto de sofrimento e dor. A interação social é viabilizada nestes espaços, pois a criança irá partilhar com outras os brinquedos e jogos ali presentes, assim como irá interagir com acompanhantes e profissionais da saúde. $O$ alívio dos efeitos emocionais e psicológicos surge como consequência do brincar e suas capacidades terapêuticas. Além disso, o lúdico acresce a possibilidade da criança de adquirir e/ou descobrir novas habilidades e aprendizagens, tanto educativas (aprender uma nova brincadeira ou jogo, por exemplo), quanto psicológicas (capacidade de enfrentamento, adaptação, aderir ao tratamento, lidar com a frustração, resiliência) e sociais (compartilhamento, interação, assertividade). Por fim, a distração é um dos recursos cognitivos que emerge com o uso da brinquedoteca. Durante a brincadeira, o lúdico, a criança se adentra, por vezes, em um mundo simbólico propício a imaginação, em que as dores e sofrimentos são colocados de lado para dar espaço à criatividade (DIETZ; OLIVEIRA, 2008; OLIVEIRA, et al., 2009; MELO; VALLE, 2010; LIMA; MAGALHÃES, 2013; LIMA, et al., 2015; VITTA, et al., 2015; LOPES; JUNIOR; OLIVEIRA, 2015; SOSSELA; SAGER, 2017). 
Tabela 2. Artigos categorizados conforme a temática da pesquisa

\begin{tabular}{|c|c|c|}
\hline $\begin{array}{c}\text { Temas investigados nos } \\
\text { artigos }\end{array}$ & Autores & $N^{o}$ \\
\hline $\begin{array}{c}\text { 1. Continuidade do } \\
\text { processo de } \\
\text { desenvolvimento infantil }\end{array}$ & $\begin{array}{c}\text { Lima et al. (2015); Lima e Magalhães (2013); } \\
\text { Dietz e Oliveira (2008); Oliveira, et al. } \\
\text { (2009); Vitta, et al. (2015); Melo e Valle } \\
\text { (2010); Sossela e Sager (2017); Lopes, Junior e } \\
\text { Oliveira (2015). }\end{array}$ & \\
\hline $\begin{array}{c}\text { 2. Humanização do } \\
\text { atendimento }\end{array}$ & $\begin{array}{c}\text { Lima e Magalhães (2013); Bustamante, et al. } \\
\text { (2014); Dietz e Oliveira (2008); Oliveira, et al. } \\
\text { (2009); Sossela e Sager (2017); Lopes, Junior e } \\
\text { Oliveira (2015); Vitta, et al. (2015). }\end{array}$ & \\
\hline 3. Interação social & $\begin{array}{c}\text { Lima, et al. (2015); Bustamante, et al. (2014); } \\
\text { Oliveira, et al. (2009); Vitta, et al. (2015); } \\
\text { Sossela e Sager (2017); Lopes, Junior e Oliveira } \\
\text { (2015). }\end{array}$ & \\
\hline $\begin{array}{c}\text { 4. Alívio dos efeitos } \\
\text { emocionais e psicológicos } \\
\text { decorrentes da internação }\end{array}$ & $\begin{array}{c}\text { Lima e Magalhães (2013); Bustamante, et al. } \\
\text { (2014); Dietz e Oliveira (2008); Melo e Valle } \\
\text { (2010); Sossela e Sager (2017). }\end{array}$ & \\
\hline 5. O lúdico como fator de \\
aprendizagem & $\begin{array}{c}\text { Dietz e Oliveira (2008); Vitta, et al. (2015); Melo } \\
\text { e Valle (2010). }\end{array}$ & \\
\hline 6. Distração & Vitta, et al. (2015); Melo e Valle (2010). & \\
\hline
\end{tabular}

Fonte: Elaborado pelos autores, 2018.

Salienta-se que, apesar da quantidade de achados iniciais a partir dos descritores, a maioria remetia-se ao brinquedo terapêutico, que diferencia-se da brinquedoteca. Enquanto a brinquedoteca hospitalar é um espaço destinado a crianças hospitalizadas, visando aproximar-se de uma normalidade vivenciada antes da hospitalização, garantindo seu desenvolvimento sadio, o brinquedo terapêutico é uma técnica que é disposta aos profissionais da saúde que atendem a criança para minimizar estresse e ansiedade perante procedimentos médicos convencionais. Diante dessa distinção, não foram inclusos artigos que tratassem somente do brinquedo terapêutico no contexto hospitalar sem que a brinquedoteca não fosse abordada em alguma sessão do artigo (DIETZ; OLIVEIRA, 2008; OLIVEIRA, et al., 2009; MELO; VALLE, 2010; LIMA; MAGALHÃES, 2013; LIMA, et al., 2015; VITTA, et al., 2015; LOPES; JUNIOR; OLIVEIRA, 2015; SOS SELA; SAGER, 2017).

Foi analisado que os artigos contemplados nessa pesquisa não foram contextualizados ou interpretados a partir da Psicologia Ambiental, sequer menciona-se como ambientes restauradores do estresse da criança hospitalizada. Portanto, este estudo, seguindo a premissa de que as brinquedotecas são espaços com capacidades de restauração psicológica do estresse, não somente das crianças, mas de seus acompanhantes, torna-se a grande contribuição teórico-prática para novas pesquisas e intervenções com olhar não somente voltado a criança, acompanhante e hospital, mas ao próprio ambiente que este indivíduos se inserem (ULRICH, 1983). 


\subsection{CONTINUIDADE NO DESENVOLVIMENTO INFANTIL}

Os estudos defendem que o lúdico oportunizado na brinquedoteca constitui-se como fundamental para o ritmo de continuidade do desenvolvimento das crianças hospitalizadas, principalmente aquelas em regime de internação intensivo (DIETZ; OLIVEIRA, 2008; OLIVEIRA, et al., 2009; MELO; VALLE, 2010; LIMA; MAGALHÃES, 2013; LIMA, et al., 2015; VITTA, et al., 2015; LOPES; JUNIOR; OLIVEIRA, 2015; SOSSELA; SAGER, 2017). Bronfenbrenner (1996) acrescenta a noção de desenvolvimento que, o indivíduo é o protagonista de seu próprio percurso desenvolvimental. Assim, o desenvolvimento é caracterizado como o processo em que os indivíduos estão suscetíveis a adquirir gradualmente uma concepção mais ampliada, diferenciada e aplicável ao meio ecológico (VITTA, et al., 2015).

$\mathrm{Na}$ maioria dos casos, a rotina hospitalar se diferencia daquela habitual, pois engloba exames médico, procedimentos dolorosos, mudança de alimentação, limitação do uso de espaços físicos e controle de visitas e isto pode comprometer o desenvolvimento físico, emocional, psicológico e emocional da criança (LOPES; JUNIOR; OLIVEIRA, 2015). Nesse processo de transição da rotina normal à rotina do hospital, a criança deixa para trás: casa, os pais, os irmãos, a escola, amigos, animais de estimação e brinquedos. Dessa forma, a brinquedoteca fornece o resgate do brincar e da criatividade através do lúdico, como elemento crucial para o desenvolvimento global da criança hospitalizada (OLIVEIRA, et al., 2009).

Como visto, embora a hospitalização desempenhe um fator de risco à criança devido a ruptura da rotina e realidade da criança, seu desenvolvimento não é interrompido (MELO; VALLE, 2010). Nesse sentido, apesar da criança necessitar adaptar-se a nova realidade, por vezes, de modo brusco, o hospital também é incluído como um contexto de promoção de desenvolvimento (SOSSELA; SAGER, 2017). Irá desenvolver e/ou aperfeiçoar, nesse espaço da brinquedoteca, a criatividade, aprendizagem, socialização, manutenção do desenvolvimento, e, simultaneamente, amenizar os possíveis traumas causados pela internação (LIMA, et al., 2015). Segundo Bronfenbrenner (1996), outro aspecto mencionado diz respeito ao desenvolvimento motor, promovido pela brinquedoteca através da exploração do espaço e objetos pertencentes.

Oliveira et al. (2009) sugere que, o hospital dispor de uma brinquedoteca não é a única preocupação existente, mas o modo como é utilizado pelos profissionais da saúde. Segundo os autores Lima e Magalhães (2013), este espaço deve ser utilizado de modo a promover a potencialização das capacidades globais da criança e de seus acompanhantes, para que se desenvolvam mesmo em condições de crise. Portanto, o lúdico configura-se como um valioso recurso terapêutico aos profissionais da saúde, e, a brinquedoteca vista como um espaço do brincar, deve ser utilizado, estimulado e valorizado corretamente como fator de proteção (DIETZ; OLIVEIRA, 2008).

\subsection{HUMANIZAÇÃO DO ATENDIMENTO}

Várias ações e modificações hospitalares tem sido realizadas em prol das crianças através do movimento de humanização hospitalar, iniciativa do Ministério da Saúde em 2000. A Lei 11.104 de 2005 demonstra a importância do brincar no contexto da saúde e a ênfase dada a ambientes que promovam saúde e qualidade de vida dentro do hospital. Essa lei assegura a obrigatoriedade de unidades de saúde que contenham regime de internação infantil instalem e implementem a brinquedoteca hospitalar. Um dos fatores que certamente influenciaram esse projeto foi a ênfase as políticas de humanização do atendimento em saúde (VITTA, et al., 2015).

A humanização ocorre não somente do atendimento em saúde, mas também da própria visão dos indivíduos acerca do hospital. A brinquedoteca fornece uma visão de que ambientes hospitalares não somente são espaços de adoecimento e sofrimento, mas de recuperação da saúde e bem-estar. Esse espaço humanizado torna a internação uma experiencia menos traumática para a criança, pois adentra a criança em um espaço que está habituada fora do contexto hospitalar. Além disso, assim como visto nas próximas categorias temáticas, possibilita melhores condições de permanência para a criança e seu acompanhante, propicia interações sociais, aprendizagem, distração e desenvolvimento infantil (LOPES; JUNIOR; OLIVEIRA, 2015). 
A humanização ocorre diante da utilização do brincar pelos próprios profissionais da saúde. Assim, promove a humanização do atendimento em saúde ao acrescentar o lúdico em sua atuação, além de incorporar a proposta de tornar a rotina da criança menos agressiva, o que também facilita a adesão ao tratamento. Outra consequência da adoção do lúdico no hospital e atendimento a criança diz respeito a própria rotina maçante do profissional da saúde. O vislumbre de uma criança hospitalizada entrando em contato com o lúdico, com o brincar, também viabiliza ao profissional uma visão humanizada acerca de sua própria atuação (VITTA, et al., 2015). Nesse sentido, a brinquedoteca não somente humaniza o espaço ofertado a criança, como os demais indivíduos ali presentes, isto é, acompanhantes e profissionais da saúde. Este espaço possibilita a interação e comunicação entre com outros acompanhantes e profissionais da saúde e facilita na realização de procedimentos médicos (DIETZ; OLIVEIRA, 2008; OLIVEIRA, et al., 2009).

Diante disso, o brincar se torna um instrumento de humanização hospitalar disponível a qualquer profissional da saúde. Caso o hospital não tenha ainda implementado a brinquedoteca, conforme prediz a lei supracitada, o brinquedo terapêutico é um método eficaz e que possibilita um atendimento humanizado. $\mathrm{O}$ brinquedo terapêutico também pode ser implementado no atendimento como complementar a brinquedoteca. Já que para utilizar a brinquedoteca a criança dispõe de horários específicos, o atendimento profissional nos horários em que a criança não faz uso da brinquedoteca pode contemplar o lúdico para dar continuidade a esta prática em saúde (LIMA; MAGALHÃES, 2013; BUSTAMANTE, et al., 2014; SOSSELA; SAGER, 2017).

\subsection{INTERAÇÃO SOCIAL}

A brinquedoteca foi caracterizada por diversos autores (OLIVEIRA, et al., 2009; BUSTAMANTE, et al., 2014; LIMA, et al., 2015; VITTA, et al., 2015; LOPES; JUNIOR; OLIVEIRA, 2015; SOSSELA; SAGER, 2017) como um espaço que promove a interação social entre criança-criança, criança-acompanhante e criança-profissional. É através dessa interação que a criança irá desenvolver habilidades sociais, como comunicação, expressão e assertividade (OLIVEIRA, et al., 2009; VITTA, et al., 2015). A criança terá que aprender a lidar com sentimentos provenientes dessa interação, como felicidade, tristeza, frustração, agressividade, medo, angustia, etc. (DIETZ; OLIVEIRA, 2008).

Contudo, não somente para a criança a interação social é dirigida como para seus acompanhantes, que poderão dialogar e trocar experiências com outros acompanhantes, auxiliando-os a adquirir maior capacidade de resiliência para suportar a situação de hospitalização da criança (BUSTAMANTE, et al., 2014; SOSSELA; SAGER, 2017). Outra interação social possível neste espaço é entre o acompanhante e profissional da saúde. Nessa interação podem ser sanadas as dúvidas que podem emergir sobre o tratamento e rotina da criança, prevalecendo a troca de informações pertinentes a internação (LIMA, et al., 2015; LOPES; JUNIOR; OLIVEIRA, 2015).

Outra interação social possível neste espaço e não foi mencionada nos achados, diz respeito a própria estabelecida entre os profissionais da saúde. Além da troca de informações e experiências, os profissionais podem discutir sobre intervenções possíveis diante de cada caso e observar a criança hospitalizada no momento das atividades na brinquedoteca. Podem ser observadas melhoras do quadro de saúde ou declínios provenientes de um tratamento não eficaz, por exemplo. Nesse sentido, propicia aos profissionais interagirem entre si e dialogar práticas em saúde visando uma melhor recuperação para o paciente (COSTA, 2007).

\subsection{ALÍVIO DOS EFEITOS EMOCIONAIS DECORRENTES DA INTERNAÇÃO}

Como já mencionado, os efeitos da hospitalização nas crianças se diferenciam dos vivenciados pelos adultos. As crianças experimentam em maior frequência o medo, ansiedade e o estresse, principalmente em 
casos de primeira internação. O medo está principalmente circundante ao tratamento e intervenções que possam causar dor e sofrimento; a ansiedade em virtude da permanência no hospital; e o estresse devido a brusca alteração e adaptação a nova rotina e contexto (DIETZ; OLIVEIRA, 2008; MELO; VALLE, 2010).

Frente a isso, o lúdico propicia uma minimização desses sintomas, demonstrando-se benéfico tanto a nível físico, psicológico quanto emocional. Isto ocorre já que a criança encontra na brinquedoteca a possibilidade de homeostase, isto é, de equilíbrio saudável por meio do brincar. Desse modo, combate ao estresse oriundo dos processos envolvidos na hospitalização (DIETZ; OLIVEIRA, 2008), além da minimização do medo, estresse e do ócio (LIMA, et al., 2015).

Principalmente o estresse é um efeito da hospitalização, pois essa experiência é totalmente desgastante para criança desde o emocional, psicológico e físico. Como a criança terá que adaptar-se rapidamente ao novo meio e realidade do hospital, o efeito mais esperado é que a criança, assim como os acompanhantes vivenciem níveis elevados de estresse. O grau de estresse dependerá da gravidade do caso, tempo de tratamento e internação, nível socioeconômico da família, atividades desempenhadas pela criança habitualmente, modo como os pais irão lidar com a situação, e, principalmente, como a criança irá expressar seus sentimentos, temores, tensões e ansiedade (LIMA; MAGALHÃES, 2013; BUSTAMANTE, et al., 2014; SOSSELA; SAGER, 2017).

Como espera-se que a brinquedoteca disponha de elementos coloridos, vibrantes, jogos e brincadeiras, possibilita que a criança vivencie outras experiências e estímulos que ultrapassam a dor e o sofrimento. Assim, os efeitos da brinquedoteca na criança são de minimização dos sintomas decorrentes da hospitalização e promoção de maior bem-estar e qualidade de vida durante o período de internação (BUSTAMANTE, et al., 2014).

\subsection{O LÚDICO COMO FATOR DE APRENDIZAGEM}

É consenso entre os autores Dietz e Oliveira (2008), Melo e Valle (2010) e Vitta et al. (2015) que o lúdico viabilizado pela brinquedoteca é uma importante ferramenta de aprendizagem no contexto hospitalar. Como a criança hospitalizada é ausentada de suas atividades educativas tradicionais, o lúdico desses espaços serve como mantenedora de atividades que estimulam o desenvolvimento intelectual da criança. A criança irá brincar e simultaneamente aprender mais sobre o mundo, tempo e espaço, irá expressar seus conhecimentos e adquirir novos a partir da interação com outras crianças e acompanhantes.

\subsection{DISTRAÇÃO}

A distração, citada por Vitta et al. (2015) e Melo e Valle (2010), refere-se a capacidade da criança em manter sua atenção direcionada a brincadeira a ponto de efetivamente distrair-se e esquecer, mesmo que temporariamente, da dor, sofrimento e ansiedade que está vivenciando devido a internação. Portanto, por meio do engajamento, motivação e imaginação durante a utilização da brinquedoteca, a criança desenvolve a capacidade de distração. A distração, diante disso, configura-se como um recurso cognitivo que visa desviar a atenção da criança através de atividades que lhe são prazerosas, distanciando-a dos aspectos agressivos e nocivos da hospitalização (VITTA, et al., 2015).

\section{DISCUSSÃO}

Através da exposição dos resultados, fica evidente que a importância da brinquedoteca abrange aspectos do desenvolvimento integral da criança, assim como melhora as condições de permanência e comunicação dos acompanhantes e viabiliza o atendimento humanizado aos profissionais da saúde. Como visto, no decorrer dos resultados algumas lacunas foram encontradas nos achados, como a falta de uma explanação acerca da importância da brinquedoteca para além da criança e seu acompanhante, mas também para o profissional da saúde e hospital propriamente dito. Outra crítica tecida diz respeito 
a abordagem epistemológica adotada pelos artigos, sem considerar a brinquedoteca enquanto espaço físico planejado a ofertar a criança e aos demais indivíduos que o usufruem a restauração psicológica do estresse. $\mathrm{O}$ ambiente físico da brinquedoteca fornece a criança elementos que possibilitam a minimização dos efeitos da internação, principalmente o estresse (DIETZ; OLIVEIRA, 2008; OLIVEIRA, et al., 2009; MELO; VALLE, 2010; LIMA; MAGALHÃES, 2013; LIMA, et al., 2015; VITTA, et al., 2015; LOPES; JUNIOR; OLIVEIRA, 2015; SOSSELA; SAGER, 2017).

A visão de ambientes restauradores somada a Teoria Bioecológica de Bronfenbrenner seria interessante para discutir teoricamente os benefícios da utilização da brinquedoteca de modo mais abrangente. Assim, demonstra-se possível alcançar a premissa de que a criança se beneficia do ambiente, que por sua vez, influencia diretamente seu comportamento e ações, ao mesmo tempo que deve-se considerar a premissa Processo, Pessoa, Contexto e Tempo proposto pelo autor supracitado (BRONFENBRENNER, 1996; ULRICH, 1983; KAPLAN, 1987).

Nesse sentido, a criança não somente está envolvida por um emaranhado de influências culturais, sociais e desenvolvimentais, como está sendo influenciada diretamente pelo próprio ambiente físico em que está inserida. Portanto, a Psicologia Ambiental inserida nestes espaços hospitalares promove a humanização e bem-estar, desde perspectivas direcionadas a pacientes e acompanhantes, até profissionais da saúde. Esta área investiga a inter-relação entre homem-ambiente e suas respectivas influencias. Sua visão de homem indica que tanto o ambiente influencia o homem, quanto o processo inverso. Assim, mesmo que emergido na inconsciência, o homem está a todo momento sofrendo a influência do ambiente (KAPLAN, 1987).

Partindo de uma abordagem psicoevolucionista, Ulrich (1983) assegura que é fundamental cercar-se de fatores que estimulam a aproximação. Estes fatores estão estritamente associados a ambientes físicos visualmente prazerosos, como é o caso da brinquedoteca, que por sua vez, proporcionam sensações de bem-estar, redução do estresse, mantêm o estado de atenção não vigilante, reduzem a ocorrência de pensamentos negativos e influenciam a moderação da excitação fisiológica (physiological arousal) (VAN DEN BERG; CUSTERS, 2011).

Mesmo inserido em um contexto permeado por aspectos físicos que remetem a doença, dor, sofrimento e adoecimento, o hospital possui potencial e capacidade para não somente proporcionar estresse, mas a redução do mesmo. Dito isto, esta pesquisa demonstrou que a brinquedoteca hospitalar promove melhorias nas condições da criança, do acompanhante, dos profissionais, sendo este um ambiente que pode ser considerado potencialmente responsável pela restauração psicológica do estresse (GRESSLER; GHUNTER, 2013).

Entretanto, atenta-se que esses ambientes devem ser planejados e repensados, com a utilização correta de materiais, jogos e brincadeira, de modo a preservar sua missão e estimular a criança durante seu desenvolvimento humano. Nesse sentido, não apenas é importante que os hospitais com regime de internação pediátricos cumpram sua obrigação de dispor a criança esses espaços de promoção de saúde e qualidade de vida, como devem ser de qualidade e funcionalidade adequados a cada situação (ULRICH, 1983).

\section{CONSIDERAÇÕES FINAIS}

Salienta-se que este artigo buscou identificar a produção de artigos científicos envolvendo a importância da brinquedoteca para o desenvolvimento infantil da criança hospitalizada, publicados em âmbito nacional entre 2008 até abril de 2018. Diante dos resultados e discussão apresentados, ficou evidente que a brinquedoteca é um tema que vem sendo discutido principalmente após o ano de 2000, quando iniciou-se os movimentos em hospitais em prol da humanização do atendimento em pediatria. Com o projeto de lei aprovado em 2005 essa humanização tornou-se viável, mas ainda enfrenta problemas na implantação das brinquedotecas devido a regimes internos e burocracias, além das problemáticas envolvendo as brinquedotecas já implementadas, porém, de modo equivocado. 
Evidenciou-se que a brinquedoteca hospitalar surge como possibilidade de humanizar o contexto e o atendimento em saúde pediátrica. Assim, a própria visão dos indivíduos acerca do hospital ser um espaço estritamente de pessoas doentes e em estado de sofrimento intensos, passa a ser reconhecida também como espaço de proteção, promoção e recuperação da saúde. Essa noção de brinquedoteca amplia aquela explanada nos achados, de que fornece benefícios principal e exclusivamente as crianças hospitalizadas e aos acompanhantes. Obviamente a brinquedoteca por ser um ambiente planejado e destinado ao público infantil possui objetivos e missões direcionadas as crianças. Contudo, como também promove adentrar acompanhantes e profissionais da saúde, seus benefícios também se ampliam.

Como visto, através da leitura sistemática dos achados foi possível identificar as temáticas mais discutidas em relação a importância da brinquedoteca hospitalar para o desenvolvimento infantil: 1) continuidade no desenvolvimento infantil; 2) humanização do atendimento; 3) interação social; 4) alívio dos efeitos emocionais e psicológicos decorrentes da internação; 5) o lúdico como fator de aprendizagem; e 6) distração. Em resumo, analisou-se que a brinquedoteca por possuir elementos e brincadeiras que remetem ao contexto normal antes da internação, possibilita uma aproximação do desenvolvimento normal da criança e atribuindo a noção de continuidade e manutenção da infância, mesmo que inserida no hospital. Como consequência disso, humaniza não somente atendimento como o contexto hospitalar, pois não somente atende as necessidades biológicas e fisiológicas das crianças em recuperação, como propicia uma melhor estadia no hospital. A interação social é viabilizada diante da noção de espaço terapêutico compartilhado, e, portanto, utilizado por outras crianças hospitalizadas e seus acompanhantes. O alívio das reações emocionais e psicológicas adentra como consequência da inserção do lúdico as atividades hospitalares, principalmente aquelas que referem-se ao medo, ansiedade e estresse. Ainda enquanto consequência, está a aprendizagem que é viabilizada perante o manuseio de novos estímulos, brincadeiras, jogos, diálogos, presentes na brinquedoteca. Por fim, a distração é mencionada como um recurso cognitivo que pode ser desenvolvimento e experienciado por qualquer criança ao direcionar a atenção as atividades na brinquedoteca e esquecendo a dor, mesmo que por pouco tempo.

Sugere-se a futuras pesquisas sanar as lacunas levantadas na discussão desta pesquisa, isto é, considerar os benefícios da brinquedoteca para uma visão ampliada a profissionais e hospital, assim como perceber a relevância do espaço físico da brinquedoteca. A dimensão física da brinquedoteca engloba iluminação, objetos, cores, brinquedos, tamanho dos objetos, quantidade, ambiente total ou parcialmente construído, dispõe de ambiente natural, etc. Verifica-se que a brinquedoteca deve ser um espaço do hospital, mas que deva ser implementado em suas mediações para proporcionar a criança o contato com elementos da natureza, como a luz solar, contato com o ar, terra, grama, vento, aproximando-se de uma realidade potencialmente vivenciada antes da internação. 


\section{REFERÊNCIAS}

BRASIL. Lei Federal n. 11.104, de 21 de março de 2005. Dispõe sobre a obrigatoriedade de instalação de brinquedotecas nas unidades de saúde que ofereçam atendimento pediátrico em regime de internação. Disponível em: http://www. planalto.gov.br/ccivil_03/_Ato2004-2006/2005/Lei/L11104.htm Acesso em: 27 abril 2018.

BRONFENBRENNER, U. A ecologia do desenvolvimento humano: experimentos naturais e planejados. Porto Alegre: Artes Médicas, 1996. 373 p.

BUSTAMANTE, V. et al. O brincar em família como possibilidade de humanização para crianças no hospital. Revista EPOS, Rio de Janeiro, v. 5, n. 2, jul./dez. 2014. Disponível em: <http://pepsic.bvsalud.org/scielo.php?script=sci_arttext\&pid=S2178-700X2014000200007\&lng=pt\&tlng=pt >. Acesso em: 27 maio 2018.

COSTA, R. P. Interdisciplinaridade e equipes de saúde: concepções. Mental, Barbacena, v. 5, n. 8, jun. 2007. Disponível em: <http://pepsic.bvsalud.org/scielo.php?script=sci_arttext\&pid=S1679-44272007000100008\&lng=pt\&tlng=pt $>$. Acesso em: 23 abril 2018.

DIETZ, K. G.; OLIVEIRA, V. B. de. Brinquedotecas hospitalares, sua análise em função de critérios de qualidade. Boletim-Academia Paulista de Psicologia, São Paulo, v. 28, n. 1, jun. 2008. Disponível em: <http://pepsic.bvsalud.org/ scielo.php?script=sci_arttext\&pid=S1415-711X2008000100012\&lng=pt\&tlng=pt>. Acesso em: 23 abril 2018.

GRESSLER, S. C.; GÜNTHER, I. de A. Ambientes restauradores: Definição, histórico, abordagens e pesquisas. Estudos de Psicologia, Natal, v. 18, n. 3, jul./set. 2013. Disponível: <http://www.scielo.br/pdf/epsic/v18n3/09.pdf >. Acesso em: 30 maio 2018.

KAPLAN, S. A esthetics, affect, and cognition: Environmental preference from an evolutionary perspective. Environment and behavior, v. 19, n. 1, jan. 1987. Disponível: <http:/journals.sagepub.com/doi/ pdf/10.1177/0013916587191001>. Acesso em: 30 maio 2018.

LIMA, M. B. S. et al. Brinquedoteca hospitalar: a visão dos acompanhantes de crianças. Psicologia: teoria e prática, São Paulo, v. 17, n. 1, jan./abr. 2015. Disponível: <http://pepsic.bvsalud.org/scielo.php?script=sci_arttext\&pi$\mathrm{d}=$ S1516-36872015000100009\&lng=pt\&tlng=pt $>$. Acesso em: 30 abril 2018.

LIMA, M. B. S.; MAGALHÃES, C. M. C. Brinquedotecas hospitalares em Belém: Criação, espaço e funcionamento. Psicologia Argumento, Curitiba, v. 31, n. 73, abr.jun. 2013. Disponível em: <http://www2.pucpr.br/reol/pb/index.php/ pa?ddl $=7832 \& d d 99=$ view $\& d d 98=$ pb $>$. Acesso em: 27 abril 2018 .

LOPES, B. A.; JUNIOR, C. R. de O.; OLIVEIRA, V. B. de. O Brincar como instrumento de resgate do cotidiano da criança hospitalizada. Boletim Academia Paulista de Psicologia, São Paulo, v. 35, n. 88, jan./jun. 2015. Disponível em: $<\mathrm{http}$ //pepsic.bvsalud.org/scielo.php?script=sci_arttext\&pid=S1415-711X2015000100007\&lng=pt\&tlng=pt $>$. Acesso em: 23 abril 2018.

LOPES, B. A.; PAULA, T. de; ANGELI, E. M. O significado das festas em uma brinquedoteca hospitalar: promoção da saúde, da cultura e da vivência da infância para crianças enfermas. Revista da SBPH, Rio de Janeiro, v. 15, n. 1, jan./jun. 2012. Disponível em: <http://pepsic.bvsalud.org/scielo.php?script=sci_arttext\&pi$\mathrm{d}=\mathrm{S} 1516-08582012000100010 \& \operatorname{lng}=\mathrm{pt} \& \mathrm{tlng}=\mathrm{pt}>$ : Acesso em: 23 abril 2018.

MELLO, C. O. et al. Brincar no hospital: assunto para discutir e praticar. Psicologia: teoria e pesquisa, São Paulo, v. 15, n. 1, jan./abr. 1999. Disponível: <http://periodicos.unb.br/index.php/revistaptp/article/view/20607/14679>. Acesso em: 22 maio 2018.

MELO, L. de L.; VALLE, E. R. M. do. A Brinquedoteca como possibilidade para desvelar o cotidiano da criança com câncer em tratamento ambulatorial. Revista da Escola de Enfermagem da USP, São Paulo, v. 44, n. 2, 2010. Disponível: $<$ http://www.scielo.br/pdf/reeusp/v44n2/39.pdf $>$. Acesso em: 20 maio 2018.

MENDES, K. D. S.; SILVEIRA, R. C. de C. P.; GALVÃO, C. M. Revisão integrativa: método de pesquisa para a incorporação de evidências na saúde e na enfermagem. Texto \& contexto enfermagem, Florianópolis, v. 17, n. 4, out./dez. 2008. Disponível em: <http://www.scielo.br/pdf/tce/v17n4/18.pdf>. Acesso em: 20 abril 2018. 
MUSSA, C.; MALERBI, F. E. K. O impacto da atividade lúdica sobre o bem estar de crianças hospitalizadas. Psicologia: teoria e prática, São Paulo, v. 10, n. 2, dez. 2008. Disponível em: $<$ http://pepsic.bvsalud.org/scielo.php?script=sci_arttext\&pid=S1516-36872008000200007\&lng=pt\&tlng=pt $>$ Acesso em: 23 abril 2018.

OLIVEIRA, L. D. B. et al. A brinquedoteca hospitalar como fator de promoção no desenvolvimento infantil: relato de experiência. Journal of Human Growth and Development, São Paulo, v. 19, n. 2, 2009. Disponível em: <http://pepsic. bvsalud.org/scielo.php?script=sci_arttext\&pid=S0104-12822009000200011\&lng=pt\&tlng=pt $>$. Acesso em: 23 abril 2018 .

SOSSELA, C. R.; SAGER, Fábio. A criança e o brinquedo no contexto hospitalar. Revista da SBPH, Rio de Janeiro, v. 20, n. 1, jan./jun. 2017. Disponível em: <http://pepsic.bvsalud.org/pdf/rsbph/v20n1/v20n1a03.pdf>. Acesso em: 23 abril 2018 .

ULRICH, R. S. Aesthetic and affective response to natural environment. In: ALTMAN, Irwin; WOHLWILL, Joachim. Behavior and the natural environment. Nova Iorque: Plenum, 1983. p. 85-120.

VAN DEN BERG, A. E.; CUSTERS, M. H. G. Gardening promotes neuroendocrine and affective restoration from stress. Journal of health psychology, v. 16, n. 1, jun. 2011. Disponível em: <http://journals.sagepub.com/doi/ abs/10.1177/1359105310365577> Acesso em: 27 abril 2018.

VITTA, A. de. et al. O brincar no contexto hospitalar na visão dos acompanhantes de crianças internadas. Journal of Human Growth and Development, v. 25, n. 1, 2015. Disponível: <http://www.revistas.usp.br/jhgd/article/ view/96766/96165>. Acesso em: 25 maio 2018.

$\begin{array}{ll}\text { Histórico } & \text { Recebido em: } 27 / 05 / 2018 \\ & \text { Revisado em: } 15 / 03 / 2019 \\ & \text { Aceito em: 22/03/2019 } \\ & \text { Concepção: MH; MLV } \\ & \text { Coleta de dados: MH. } \\ & \text { Análise de dados: MH; MLV. } \\ \text { Elaboração do manuscrito: MH. } \\ \text { Revisões de conteúdo intelectual importante: MH; SF; MLV. } \\ \text { Aprovação final do manuscrito: MH. } \\ \\ \text { Financiamento } & \text { Coordenação de Aperfeiçoamento de Pessoal de Nível Superior (CAPES).- bolsa DS. }\end{array}$

